\title{
Species-area relationship within and across functional groups at alpine grasslands on the northern Tibetan Plateau, China
}

\author{
ZHOU Nan",2 (D http://orcid.org/oooo-0oo2-9816-2678; e-mail: zhoun.13s@igsnrr.ac.cn \\ WU Jian-shuang 1,3 (iD http://orcid.org/oooo-0002-6768-8255; e-mail: wujs.o7s@igsnrr.ac.cn \\ SHEN Zhen-xi ${ }^{1}$ iDttp://orcid.org/oooo-ooo2-3485-5459; e-mail: shenzx@igsnrr.ac.cn

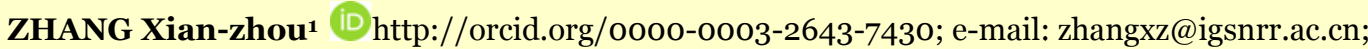 \\ YANG Peng-wan ${ }^{1,2}$ iD http://orcid.org/oooo-ooo3-1045-5714; e-mail: yangpengwan2012@126.com \\ 1 Lhasa National Ecological Research Station, Key Laboratory of Ecosystem Network Observation and Modelling, \\ Institute of Geographic Sciences and Natural Resources Research, Chinese Academy of sciences, Beijing 100101, China \\ 2 University of Chinese Academy of Sciences, Beijing 100049, China \\ 3 Functional Biodiversity, Dahlem Centre of Plant Sciences, Free University of Berlin, 14195 Berlin, Germany
}

Citation: Zhou N, Wu JS, Shen ZX, et al. (2016) Species-area relationship within and across functional groups at alpine grasslands on the Northern Tibetan Plateau, China. Journal of Mountain Science 13(2). DOI: 10.1007/s11629-014-3166-2

(C) Science Press and Institute of Mountain Hazards and Environment, CAS and Springer-Verlag Berlin Heidelberg 2016

\begin{abstract}
The species-area relationship (SAR) is one of the most fundamental concepts in community ecology and is helpful for biodiversity conservation. However, few studies have systematically addressed this topic for different alpine grassland types on the Tibetan Plateau, China. We explored whether the plant composition of different functional groups affects the manner in which species richness increases with increasing area at scales $\leq 1.0 \mathrm{~m}^{2}$. We also compared species richness $(S)$ within and across forbs, legumes, sedges and grasses, with sampling subplot area $(A)$ increasing from $0.0625 \mathrm{~m}^{2}$ to $1.0 \mathrm{~m}^{2}$ between alpine meadow and steppe communities. We applied a logarithmic function $\left(S=b_{o}+b_{1} \ln A\right)$ to determine the slope and intercept of SAR curves within and across functional groups. The results showed that the logarithmic relationship holds true between species richness and sampling area at these small scales. Both the intercept and slope of the logarithmic forbs-area curves are significantly higher than those for the three other functional groups $(P<0.05)$. Forb accounts for about $91.9 \%$ of the variation in the intercept and $75.0 \%$ of the variation in the slope of the SAR curve when all
\end{abstract}

Received: 20 January 2015

Accepted: 4 May 2015 functional groups' data were pooled together. Our results indicated that the different SAR patterns should be linked with species dispersal capabilities, environmental filtering, and life form composition within alpine grassland communities. Further studies on the relationship between species diversity and ecosystem functions should specify the differential responses of different functional groups to variations in climate and anthropogenic disturbances.

Keywords: Changtang Nature Reserve; Complementary response; Plant functional groups; Plant life forms; Species coexistence

\section{Introduction}

The species-area relationship (SAR) is one of the most general, yet variable protean patterns in ecology (Lawton 1999; Lomolino 2000; Whittaker and Triantis 2012; Whittaker et al. 2014). Ecologists and biogeographers often use it to demonstrate how species richness $(S)$ increases with sampling area $(A)$. Both the forms of SARs 
and their parameters have received increasing attention over the past decades (Scheiner 2003; Tjorve 2003; Gray et al. 2004; Turner and Tjorve 2005; Tjorve 2009; Whittaker et al. 2014). It is important to systematically understand what factors control SAR across different habitats (Tjorve and Tjorve 2008; Tjorve 2009; Whittaker and Triantis 2012; Gerstner et al. 2014; Whittaker et al. 2014).

The SAR is a key biodiversity conservation tool used to project species losses caused by anthropogenic or natural disturbances (Tjorve 2009; Whittaker and Triantis 2012). Scheiner (2003) identified six different constructs for SAR functions but found that was hard to reach a common definition for each of these SAR forms (Scheiner 2009). Parameters of SAR curves, such as intercept and slope, have profound implications for conservation; in a natural plant community, these parameters are likely dependent on a range of biotic and abiotic factors, including the successional stage of communities (Leps and Stursa 1989; Houle 1990; Carey et al. 2006), plantto-plant interactions (competition or facilitation) (Shmida and Wilson 1985; Auerbach and Shmida 1987), and the spatial scale of the system or taxon studied (Shmida and Wilson 1985; Auerbach and Shmida 1987; Turner and Tjorve 2005). In addition, fieldwork procedures, including plot selection, sampling, and developing the shape (circle, square or rectangle) of the sampling units, may affect the SAR parameters for a specific community (Turner and Tjorve 2005). Too small of a sampling area and incomplete species identification will occur, resulting in underestimated species richness (Barnett and Stohlgren 2003; Turner and Tjorve 2005). Niche overlapping and differentiation control on species coexistence and ecological functioning at a basic level (Shmida and Wilson 1985; Auerbach and Shmida 1987). Therefore, a cross-plant functional groups approach is essential, even at very small scales, to accurately assess species richness and understand species coexistence (Yu et al. 2008).

Alpine grasslands on the Tibetan Plateau are extremely sensitive and vulnerable to anthropogenic disturbances (primarily livestock grazing) in the face of continually warming temperatures. Recently, many studies have focused on species richness ( $\mathrm{Wu}$ et al. 2012; $\mathrm{Wu}$ et al. 2013b) and community productivity (Yang et al. 2009; Hu et al. 2010; Yang et al. 2010), as well as their relationships across different spatial scales in alpine grasslands on the Tibetan Plateau (Ma et al. 2010b; Wang et al. 2013; Wu et al. 2014b). Wu et al. (2014b) even found that plant functional group composition, an ordinal variable with plants provisionally scored as 1-xerophytes; 2-mesophytes; 3 -hygrophytes, is as important as precipitation in explaining the spatial variation of aboveground net primary productivity across zonal alpine grassland types in this region. Wu et al. (2013a) approached biomass allocation systematically and revealed that individuals in the Tibetan alpine grasslands respond to decreasing precipitation in allometric ways but that the response vary among forbs, legumes, sedges and grasses. The number and extent of ecological benefits accrued by excluding grazing are also dependent on plant species composition between sites and grassland types; plants seem to specifically respond to prolonged grazing exclusion in discrete ways among different functional groups (Wu et al. 2014d). These findings indicate differential niches or functional traits are likely related to plant coexistence and community structures. These compositional changes of plant functional groups likely have profound influences on the ecological functions of the Tibetan alpine grasslands (Wu et al. 2013b; Wu et al. 2014b). However, few studies have directly examined whether or how functional group composition can modify the form and parameters of the community SARs of zonal alpine grasslands on the Tibetan Plateau (Yu et al. 2008; Morgan et al. 2011).

In this study, we aim (1) to clarify the specific forms of SAR within and across four functional groups (grasses, sedges, legumes and forbs) at scales $\leq 1.0 \mathrm{~m}^{2}$ for alpine meadow and alpine steppe communities; (2) to examine whether the slopes and intercepts of the SAR curves vary between alpine meadows and steppes; and (3) to estimate the relative contributions of each functional group to the slope and intercept of the SAR at the community level.

\section{Materials and Methods}

\subsection{Study area}

Alpine meadow dominated by Kobresia 
pygmaea and alpine steppe dominated by Stipa purpurea are the two most widely distributed grassland types on the Qinghai-Tibetan Plateau of China (Yang et al. 2009; $\mathrm{Li}$ et al. 2011; Wu et al. 2013b). Alpine pastures on the Plateau are traditionally grazed by yaks and/or sheep and are managed by single or multiple families (Cao et al. 2011; Cao et al. 2013). Livestock grazing can affect plant species composition, which influences the form and parameters of SAR in many habitats (Hiernaux 1998; de Bello et al. 2007; Chen et al. 2008). However, there is lack of available information on the selective grazing behaviors of domestic yaks and sheep on the Northern Tibetan Plateau. Moreover, it is so difficult to obtain existing accurate data on grazing regimes (timing, intensity and frequency) that we cannot yet quantify the influence of large herbivores on species composition changes in this region (Wu et al. 2013b). Many large enclosures have been built since 2006 to protect healthy pastures in this region and to promote the recovery of degraded ones (Wu et al. 2013b; Wu et al. 2014d). Grazing exclusion for less than five years does not appear to significantly change the relative contributions of different functional groups to species richness at the community level $(\mathrm{Wu}$ et al. 2013b), but productivity might be affected by prolonging the duration of grazing exclusion because of the relationship between different niches and water use (Wu et al. 2014d). Therefore, to avoid the undetermined influence of livestock grazing on plant community composition, we chose to study communities with apparently healthy physiognomy. These communities had been excluded from livestock grazing for at least seven years before this study in 2013. We conducted field surveys on different functional groups' compositions at a total of five alpine meadow sites and four alpine steppe sites in total (Table 1).

\subsection{Field Survey}

Whether and how sampling design influences the identification of SAR patterns for vegetation has long been a topic of discussion (Scheiner 2003, 2004; Ulrich and Buszko 2007; Keeley and Fotheringham 2009; Dengler and Oldeland 2010). Stohlgren et al. (1995) found that a square plot typically captures fewer species than a long, thin rectangle due to the lower ratio of perimeter to surface area in the square. However, Keeley and Fotheringham (2009) reported no significant difference between the species richness of square and rectangular quadrats. Scheiner (2003) divided the types of SARs into two groups, one with contiguous and the other with non-contiguous plots. At small spatial scales, SAR is frequently constructed by a sequential accumulation of replicated plots (Ulrich and Buszko 2007). A contiguous plot design is extremely importance because the plots of a contiguous array are prone to pseudo-replication (Hurlbert 1984). Spatial autocorrelation is another inevitable problem when smaller subplots are nested within the larger main plots of SAR studies (Stohlgren et al. 1995). In addition to autocorrelation and pseudo-replication, where to begin the investigation and whether to place subplots randomly within the study might introduce additional biases (Turner and Tjorve 2005). All of these factors were taken into account when we applied the new sampling procedure as described below to our study site.

First, we chose a $0.25 \mathrm{~m} \times 0.25 \mathrm{~m}$ subplot as the basic sampling unit and a $1.0 \mathrm{~m} \times 1.0 \mathrm{~m}$ quadrat as the main plot. There areas represented the smallest and largest quadrats, respectively, for harvesting biomass and estimating species richness in recent studies on the Tibetan Plateau (Ma et al. 2010b; Wu et al. 2013b). At each site, we chose a

Table 1 Information on geological location and species richness (SR) for the functional groups legumes, sedges, grasses and forbs and for all plants sampled at the five Kobresia pygmaea-dominated alpine meadows (AM) and the four Stipa purpurea-dominated alpine steppes (AS)

\begin{tabular}{|c|c|c|c|c|c|c|c|c|}
\hline \multirow{2}{*}{ Site-ID } & \multirow{2}{*}{ Longitude } & \multirow{2}{*}{ Latitude } & \multirow{2}{*}{ Altitude (m) } & \multicolumn{5}{|c|}{ Number of species } \\
\hline & & & & Total & Legumes & Sedges & Grasses & Forbs \\
\hline $\mathrm{AM}-1$ & $92^{\circ} 18^{\prime} 46.51^{\prime \prime}$ & $32^{\circ} \mathrm{O}^{\prime} \mathrm{O} 1.45^{\prime \prime}$ & 4611 & 20 & 1 & 4 & 2 & 13 \\
\hline $\mathrm{AM}-2$ & $92^{\circ} 09^{\prime} 01.58^{\prime \prime}$ & $31^{\circ} 16^{\prime} 16.57^{\prime \prime}$ & 4424 & 19 & 2 & 3 & 3 & 11 \\
\hline $\mathrm{AM}-3$ & $91^{\circ} 57^{\prime} 60.53^{\prime \prime}$ & $31^{\circ} 22^{\prime} 58.01^{\prime \prime}$ & 4508 & 31 & 4 & 3 & 4 & 20 \\
\hline $\mathrm{AM}-4$ & $92^{\circ} 05^{\prime} 00.74^{\prime \prime}$ & $31^{\circ} 17^{\prime} 11.90^{\prime \prime}$ & 4439 & 30 & 4 & 3 & 3 & 20 \\
\hline $\mathrm{AM}-5$ & $91^{\circ} 54^{\prime} 28.25^{\prime \prime}$ & $32^{\circ} 18^{\prime} 12.74^{\prime \prime}$ & 4686 & 22 & 2 & 3 & 2 & 15 \\
\hline $\mathrm{AS}-1$ & $90^{\circ} 48^{\prime} 15.00^{\prime \prime}$ & $31^{\circ} 24^{\prime} 54.00^{\prime \prime}$ & 4586 & 27 & 4 & 3 & 5 & 15 \\
\hline $\mathrm{AS}-2$ & $90^{\circ} 18^{\prime} 39.40^{\prime \prime}$ & $31^{\circ} 23^{\prime} 28.68^{\prime \prime}$ & 4597 & 20 & 1 & 3 & 3 & 13 \\
\hline $\mathrm{AS}-3$ & $88^{\circ} 47^{\prime} 57.25^{\prime \prime}$ & $33^{\circ} 12^{\prime} 24.94^{\prime \prime}$ & 4949 & 14 & 0 & 3 & 3 & 8 \\
\hline $\mathrm{AS}-4$ & $87^{\circ} 15^{\prime} 24.58^{\prime \prime}$ & $31^{\circ} 47^{\prime} 47.49^{\prime \prime}$ & 4531 & 13 & 1 & 2 & 3 & 7 \\
\hline
\end{tabular}


relative homogeneous area of approximately $200 \mathrm{~m}$ $\times 200 \mathrm{~m}$, through which we randomly placed a 100 $\mathrm{m}$ transect line. We then labelled five locations at 20-m intervals along this line. At each location, we divided the $1.0-\mathrm{m}^{2}$ main plot into 16 basic units without overlap or gaps between subplots. To avoid an underestimation of species richness (Barnett and Stohlgren 2003; Turner and Tjorve 2005), we identified the species of all individuals occurring within each subplot as carefully as possible. Then, we pooled the species records according to the subplots shown in Figure 1. Thus, species lists for sequential subplots of $1,2,3,4,6,8,9,12$, and 16 contiguous basic sampling units, ranging from $0.0625 \mathrm{~m}^{2}$ to $1.0 \mathrm{~m}^{2}$, were well prepared for further analyses in this study.

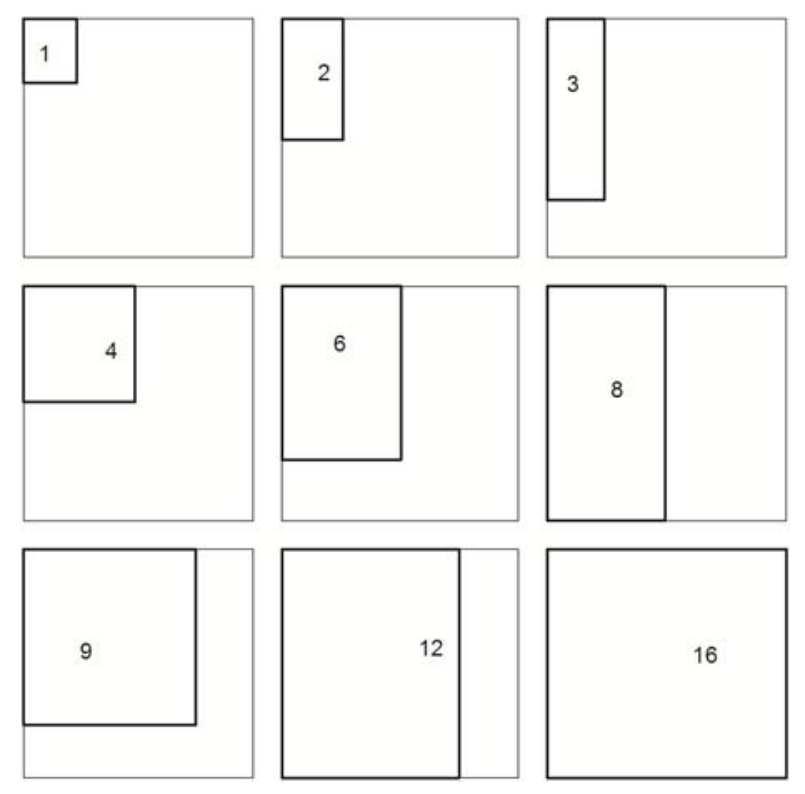

Figure 1 At each site, we chose a relatively homogeneous area through which we randomly placed a $100 \mathrm{~m}$ transect line. Five locations were systemically labelled at $20 \mathrm{~m}$ intervals along the line. At each location, basic units ( 1 basic unit $=0.0625 \mathrm{~m}^{2}$ ) were aligned to form contiguous subplots, labelled as sampling units $1,2,3,4,6,8,9,12$, and 16 above. These sampling units were nested into the $1.0 \mathrm{~m}^{2}$ main plot to reveal how species richness increases with sampling area at small scales.

Ramsay and Oxley (1997) proposed a growth form classification for ten forms found within grassland communities: stem rosettes, basal rosettes, tussocks, acaulescent rosettes, cushions and mats, upright shrubs, prostrate shrubs, erect herbs, prostrate herbs, and trailing herbs. A quantitative determination of plant composition is important to better understand both community structure and ecosystem functions. However, there is no comparable standard classification available for alpine plants in Tibetan grasslands. Ma et al. (2010a) and $\mathrm{Wu}$ et al. (2013a) have attempted to rectify this situation by confirming that forbs, legumes, sedges and grasses respond to environmental gradients on the northern Tibetan Plateau using varied but optimized strategies of biomass allocation. Wu et al. (2014d) further found these functional groups respond differently to prolonged grazing exclusion. Therefore, in this study, we followed the standard derived in previous studies (Ma et al. 2010a; Wu et al. 2013a; Wu et al. 2014b; $\mathrm{Wu}$ et al. 2014d) and categorized species into forbs, legumes, grasses or sedges to determine whether and how plant composition influences the SAR of alpine meadow and steppe communities. We calculated the mean values and standard errors of species richness at the functional group level using observations from the five main plots at each site. A list of Latin name for species occurring at the five alpine meadows (25 main plots) and the four alpine steppes (20 main plots) is shown in Appendix 1.

\subsection{Data Analyses}

We agree with Scheiner (2003) that SAR takes a variety of forms, from sigmoid to semi-logarithmic to $\log -\log$, and that no common understanding exists on the underlying mechanisms for these variations (Gray et al. 2004). The power law $S=\mathrm{c} A^{\mathrm{z}}$ (Arrhenius 1921) and the logarithmic function $S=b_{0}$ $+b_{1} \ln (A)$ (Gleason 1922, 1925) are the two most commonly used convex-upward curves without asymptote regressions used in SAR studies. Some ecologists recommended the latter function, which is a semi-logarithmic regression (Rejmének and Rosén 1992; Scheiner 2003; Gray et al. 2004). Following this recommendation, we used the semi-logarithmic regression to determine the slope $\left(b_{1}\right)$ and intercept $\left(b_{o}\right)$ of the SAR curves for each functional group and for overall species within the five replicated locations at each meadow and steppe site in this study. In total, we obtained 25 slope-intercept pairs for alpine meadows and 20 pairs for alpine steppes. Next, we employed a one-way analysis of variance (ANOVA) to examine whether there were significant differences in the intercept or slope within and across functional groups between meadows and 
steppes. We also used species richness mean values for all subplots to produce SAR figures for forbs, legumes, sedges and grasses at each main plot site. Based on site mean values, we produced general SAR figure within and across functional groups for alpine meadows and steppes on the Northern Tibetan Plateau. Finally, with species richness from the nine sample sites pooled together, we applied stepwise multiple linear regressions to determine which functional group contributes the most to the general SAR of alpine plant communities at the two grassland types on the Tibetan Plateau.

Statistical analyses were performed in SPSS 17.0 (SPSS Inc., Chicago, IL, USA), and figures were plotted in SigmaPlot 10.0 (Systat Software Inc., Chicago, IL, USA).

\section{Results}

\subsection{Species richness within and across functional groups at the nine sites}

Considerable variation exists in the richness of forbs and overall plants within communities across both alpine meadow and steppe sites (Table 1). Overall species richness across sites ranged from 19 to 31 for meadow communities and from 13 to 27 for steppe communities. On average, forbs accounted for approximately $64.7 \%$ and $58.1 \%$ of the overall richness of plants across meadow and steppe sites, respectively. No evident difference in the richness of sedges and grasses across sites exist in either meadow or steppe communities. Mean richness values of sedges and grasses across the Northern Tibetan Plateau were 3 and 3.1, respectively.

\subsection{The SARs within and across functional groups at meadows and steppes}

Logarithmic SAR curves fit well in both alpine meadow and steppe communities for both overall species and functional groups (Table 2 and Figure 2a). Similarly, significant logarithmic SAR values were also obtained for forbs, legumes, sedges and grasses (Table 2 and Figures $1 \mathrm{~b}-\mathrm{e}$ ). The intercept $b_{o}$ values of overall SAR at the five meadow sites ranged from 11.81 to 18.56 and accounted for $62 \%$

Table 2 Parameter estimates of the species-life form-area relationships using the logarithmic model $\left(S=b_{0}+b_{1} \ln A\right)$ at the five alpine meadow sites and the four alpine steppe sites. $S$, species richness or species number belonging to a given life form; $A$, subplot size $\left(\mathrm{m}^{2}\right)$. For this study, species have been divided into four functional groups: forb, legume, sedge and grass.

\begin{tabular}{|c|c|c|c|c|c|c|c|c|}
\hline \multirow{2}{*}{ Series } & \multicolumn{4}{|c|}{ Alpine meadow } & \multicolumn{4}{|c|}{ Alpine steppe } \\
\hline & $b_{0}$ & $b_{1}$ & $\operatorname{Adj} \cdot R^{2}$ & $P$ & $b_{0}$ & $b_{1}$ & $\operatorname{Adj} \cdot R^{2}$ & $P$ \\
\hline \multirow{5}{*}{ Species-area } & 12.84 & 2.41 & 0.98 & $<0.0001$ & 14.80 & 2.09 & 0.95 & $<0.0001$ \\
\hline & 11.81 & 2.113 & 0.97 & $<0.0001$ & 10.62 & 2.09 & 0.99 & $<0.0001$ \\
\hline & 18.26 & 3.11 & 0.99 & $<0.0001$ & 10.54 & 1.66 & 0.93 & $<0.0001$ \\
\hline & 18.56 & 2.72 & 0.90 & $<0.0001$ & 9.75 & 1.91 & 0.97 & $<0.0001$ \\
\hline & 16.49 & 3.04 & 0.98 & $<0.0001$ & & & & \\
\hline \multirow{5}{*}{ Forb-area } & 7.51 & 1.53 & 0.94 & $<0.0001$ & 7.24 & 1.30 & 0.94 & $<0.0001$ \\
\hline & 7.27 & 1.38 & 0.97 & $<0.0001$ & 5.60 & 1.49 & 0.99 & $<0.0001$ \\
\hline & 11.06 & 2.06 & 0.99 & $<0.0001$ & 5.17 & 0.99 & 0.96 & $<0.0001$ \\
\hline & 11.37 & 1.94 & 0.99 & $<0.0001$ & 4.45 & 0.89 & 0.97 & $<0.0001$ \\
\hline & 8.86 & 1.70 & 0.94 & $<0.0001$ & & & & \\
\hline \multirow{5}{*}{ Legume-area } & 0.90 & 0.26 & 0.91 & $<0.0001$ & 1.72 & 0.22 & 0.77 & 0.0012 \\
\hline & 0.39 & 0.18 & 0.75 & 0.0016 & 0.31 & 0.15 & 0.41 & 0.0372 \\
\hline & 1.90 & 0.19 & 0.63 & 0.0068 & & & & \\
\hline & 2.54 & 0.33 & 0.89 & $<0.0001$ & 0.27 & 0.14 & 0.44 & 0.0302 \\
\hline & $3 \cdot 37$ & 0.61 & 0.86 & 0.0002 & & & & \\
\hline \multirow{5}{*}{ Sedge-area } & 2.76 & 0.31 & 0.83 & 0.0004 & 2.11 & 0.19 & 0.70 & 0.0030 \\
\hline & 2.24 & 0.15 & 0.83 & 0.0004 & 1.64 & 0.05 & 0.37 & 0.0472 \\
\hline & 1.90 & 0.09 & 0.54 & 0.0149 & 2.24 & 0.38 & 0.87 & 0.0002 \\
\hline & 1.91 & 0.15 & 0.37 & 0.0472 & 2.01 & 0.43 & 0.74 & 0.0019 \\
\hline & 2.06 & 0.36 & 0.83 & 0.0002 & & & & \\
\hline \multirow{5}{*}{ Grass-area } & 1.67 & 0.31 & 0.93 & $<0.0001$ & 3.67 & 0.35 & 0.89 & $<0.0001$ \\
\hline & 1.91 & 0.40 & 0.95 & $<0.0001$ & 2.54 & 0.32 & 0.88 & 0.0001 \\
\hline & 3.39 & 0.78 & 0.93 & $<0.0001$ & 3.13 & 0.28 & 0.68 & 0.0040 \\
\hline & 2.79 & 0.29 & 0.60 & 0.0090 & 2.95 & 0.42 & 0.87 & 0.0001 \\
\hline & 2.17 & 0.51 & 0.83 & 0.0004 & & & & \\
\hline
\end{tabular}



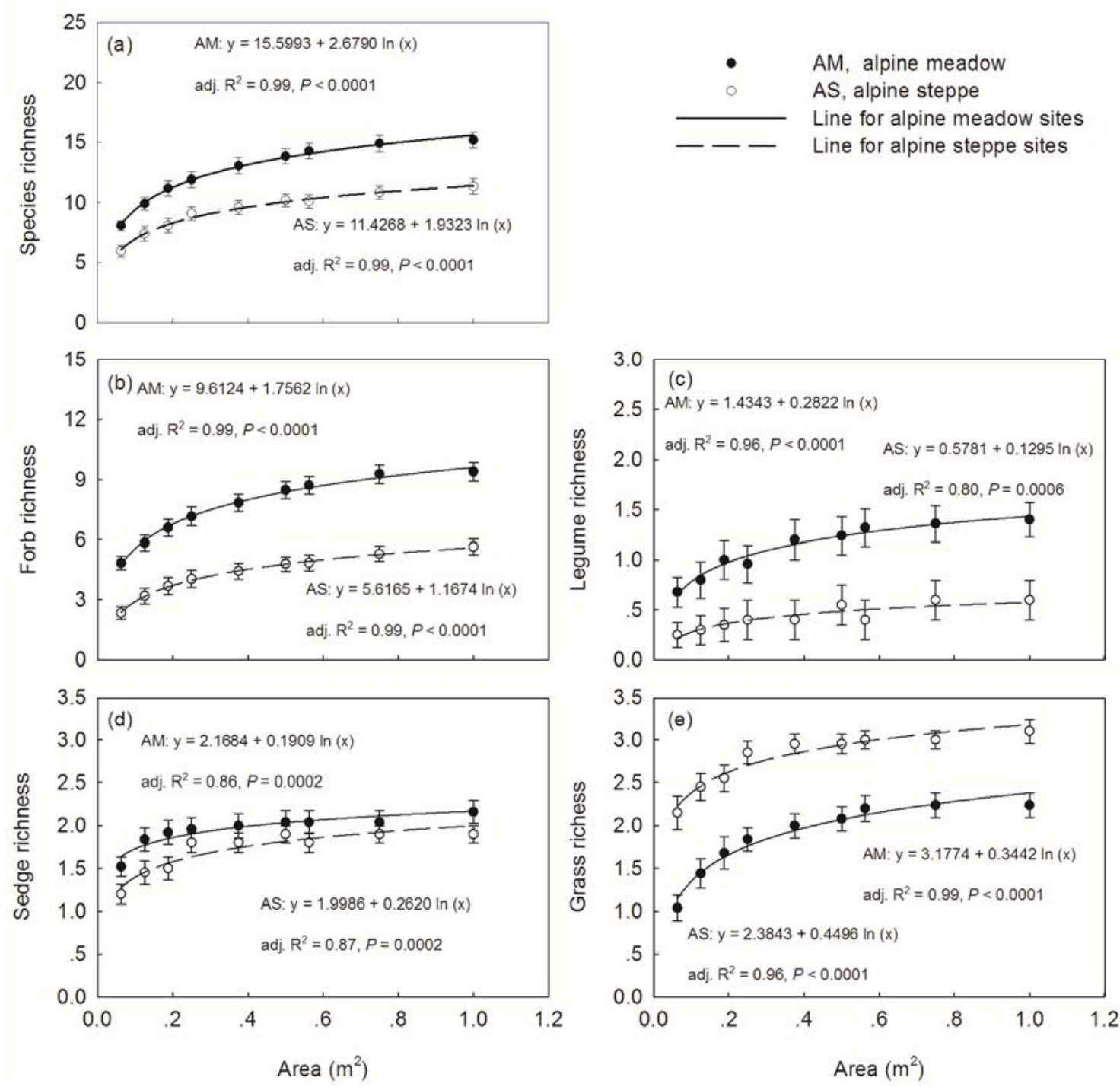

Figure 2 Species-area relationships for alpine meadow (AM, closed circle and solid line) and alpine steppe (AS, open circle and dashed line) ecosystems for all species (a), forbs (b), legumes (c), sedges (d) and grasses (e). The logarithmic function $S=b_{o}+b_{1} \ln (A)$ was used to fit each curve. $S$, species richness; $A$, subplot area.

to $75 \%$ of all the plants occurring within the sampled plots. Across the four steppe sites, the intercept values ranged from 9.75 to 14.80 and accounted for $53 \%$ to $75 \%$ of each site's richness (Tables 1-2 and Figure 2). Similarly, the mean values of the intercept $b_{o}$ for forbs were 9.21 and 5.61 , accounting for $59 \%$ and $55 \%$ of forb richness across meadow and steppe sites, respectively. The means of the intercept $b_{o}$ values for legumes, sedges and grasses accounted for an average of $71 \%$, $68 \%$ and $87 \%$ of their richness within meadows, and for $34 \%, 75 \%$ and $90 \%$ of their richness within steppes, respectively. Only the slopes $b_{1}$ values for overall plants and forb richness curves were larger than 1.o (Table 2 and Figures 1a-b).

\subsection{Comparisons of the parameters of SAR's between meadows and steppes}

Based on the well-fitted logarithmic functions shown in Table 2, the mean values of the $b_{o}$ and $b_{1}$ values of the SAR curves for overall plants and forbs within alpine meadows were significantly higher than those for alpine steppes ( $p<0.05$, Figure 3). The $b_{o}$ and $b_{1}$ values of the curves for forbs were also significantly higher than those for legumes, sedges and grasses in both meadows and steppes $(p<0.05$, Figure 3). Except for the $b_{0}$ for grasses, which was also significantly higher than that for legumes in alpine steppes $(p<0.05$, Figure 3a), no significant difference in either $b_{o}$ or $b_{1}$ among legumes, sedges 

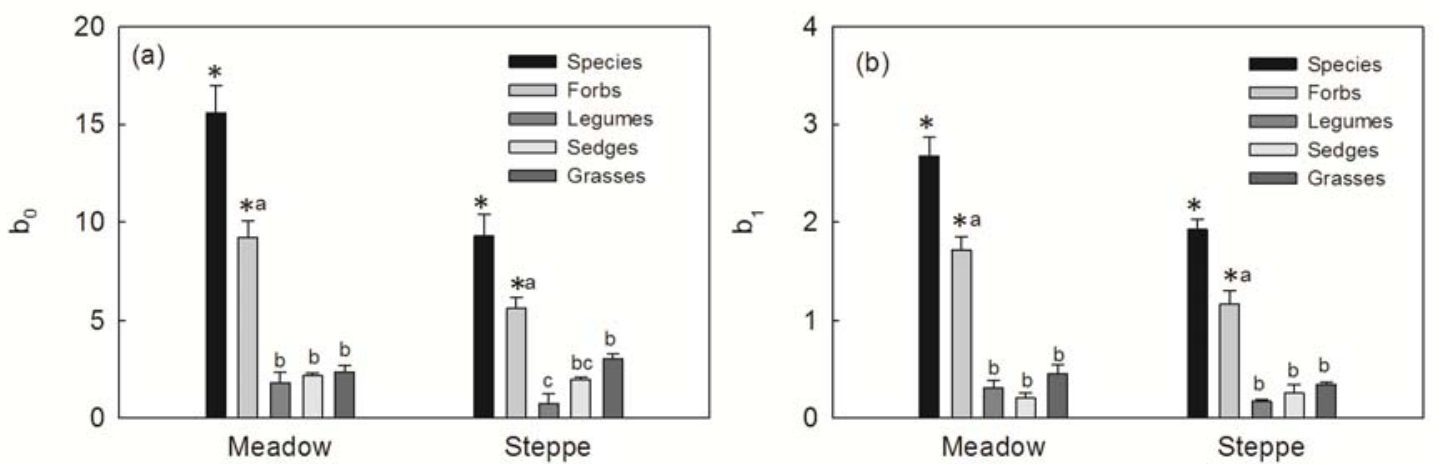

Figure 3 Comparisons of the intercept $b_{0}$ (a) and slope $b_{1}$ (b) of the logarithmic species-area relationships (SARs) within and across the four functional groups: forbs, legumes, sedges and grasses. Both $b_{o}$ and $b_{1}$ were derived from the logarithmic curve $S=b_{0}+b_{1} \ln (A)$ derived from the five meadows and four steppes in Table 2. '*' indicates a significant difference between alpine meadow and steppe sites. Different letters over the standard error (S.E.) bars indicate significant differences (at $p<0.05$ ) among functional groups within a given grassland type. One-way analysis of variance (ANOVA) with a Scheffe-test was used.

and grasses existed $(p>0.05)$. The stepwise multiple regressions showed that forbs alone accounted for approximately $91.9 \%$ of the SAR curves' intercept location and $75.0 \%$ of its slope when species richness data from both alpine meadows and steppes were combined (Table 3).

\section{Discussion}

SAR is one of the most basic characteristics of plant communities and incredibly important to researchers' understanding of the determinants of species coexistence (Olsen and Klanderud 2014). In recent years, whether species richness within a given community is the result of stochastic events such as the dispersal process or the result of environmental filtration and niche differentiations when plant individuals are recruited from the regional species pool has been rigorously debated (He and Hubbell 2011). In this study, we demonstrated how species richness within and across functional groups of forbs, legumes, sedges and grasses increased with sampling area across very small spatial scales in alpine meadow and steppe communities on the Northern Tibetan Plateau. We found that semi-logarithmic regressions nicely fit the richness of overall plants and the four functional groups mentioned above (Table 2 and Figure 2). Additionally, we found that forbs contributed more to both the intercept and the slope of the derived SAR curve compared to other functional groups in the Tibetan alpine grasslands (Table 3). This funding was consistent with the proportion of forbs' species richness at the community level (Table 1). Forbs seem to be richer within both meadows and steppes compared to legumes, sedges and grasses; however, they are not the dominant species in either alpine meadow or steppe communities in this region (Wu et al. 2013a; $\mathrm{Wu}$ et al. 2014b). On the Tibetan Plateau, alpine meadows are dominated by Kobresia pygmaea, while alpine steppes are dominated by Stipa purpurea (Li et al. 2011; Wu et al. 2013b). Both the relative frequency of forbs and the proportion of their biomass within the whole community are much lower than those for sedges in meadows and grasses in steppes (Wu et al. 2012; Wu et al. 2014c;

Table 3 Results of stepwise multiple regressions for the intercept and slope of the logarithmic function $S=b_{0}+b_{1} \ln (A)$ (meadow and steppe data are pooled together). Dependent variables were the SARs' intercepts $(n=$ 9) and slopes $(n=8)$ for alpine grassland communities; independent variables were the intercepts and slopes of the life form SARs for forbs, legumes, sedges and grasses listed in Table 2.

\begin{tabular}{|l|l|l|l|l|}
\hline Dependent & Independent & $P$ & $R^{2}$ & $R^{2}$ \\
\hline Intercept $b_{0}$ & Forb & $<0.001$ & 0.919 & \\
& Forbs + Sedges & $<0.001$ & 0.973 & 0.054 \\
\hline \multirow{2}{*}{ Slop $b_{1}$} & Forbs + Sedges + Grasses & $<0.001$ & 0.997 & 0.024 \\
& Forb & 0.005 & 0.750 & \\
& Forbs + Sedges & 0.001 & 0.829 & 0.178 \\
\hline
\end{tabular}


Wu et al. 2014d).

To better understand this issue, we turn to the two prevailing theories about plant community assembly. Neutral theory emphasizes that species richness in a given plant community is mainly determined by stochastic events, such as dispersal from the regional species pool (Bell 2001); while niche theory states that diversity is the result of environmental filtrations and biotic interactions (Chase and Myers 2011). At large scales, species recruitment and establishment in natural grasslands can be limited by habitat heterogeneity, while at small scales the community assembly is also mediated by biotic interactions (competition or facilitation) among plant individuals (Olsen and Klanderud 2014). Therefore, the two theories are not necessarily mutually exclusive, and stochastic processes, environmental filters (temperature, precipitation, moisture and nutrients in soils), and biotic interactions may simultaneously govern local species richness and composition (Lortie et al. 2004). For example, Chiarucci et al. (2006) suggested that the intercepts and slopes of SAR curves were dependent on habitat types and plant community properties. In our results, we found that both the slopes and intercepts of the SAR curves for all species and forbs were significantly higher in alpine meadows than in alpine steppes (Figure 3 and Table 2). Cold and humid meadows are reported to have more species than warm and arid steppes on the Northern Tibetan Plateau, where precipitation primarily drives the spatial distribution and ecological function of zonal alpine vegetation types ( $\mathrm{Hu}$ et al. 2010; $\mathrm{Wu}$ et al. 2012; Shi et al. 2014; Wu et al. 2014b). Desilets and Houle (2005) also found that the slopes of varying SAR curves were positively related to soil resource availability along environmental gradients. Alpine meadows have higher nutrient availability within top-soils (o-20 cm depth) than alpine steppes in this region (Yang et al. 2009; Wu et al. 2012; Wu et al. 2013b). Therefore, differences in the parameters of our semi-logarithmic SARs might be partly due to the differences in meadow and steppe habitat properties when looked at from the perspective of environmental filtration.

Species dispersal capability should be considered along with habitat heterogeneity because each factor alone is insufficient to explain specie richness. However, together, these factors may be sufficient to describe SAR (Shen et al. 2009). Functional traits are related to plant growth, reproduction and survival; therefore, to some extent, they can reflect environmental filtration, biotic interactions and plant adaptation strategies (Stegen and Swenson 2009; Cadotte et al. 2013). Ma et al. (2010a) found that, for the perennial herbaceous plants, the reproductive outputs decrease, fine roots increase and leaf fractions remain constant along an increasing elevation gradient in the Central Tibetan Plateau. Differences in functional traits or groups can also provide useful clues to understanding plant community reassembly at different spatial scales and evolutional stages (Hedberg et al. 2014). The types of plant-to-plant interactions (competition or facilitation) mainly shape SAR at the community level because different plant functional groups have evolved specific strategies to survive in a given habitat (Leps and Stursa 1989). Hence, we should pay more attention to the relative importance of different functional groups to species coexistence within given communities as advocated by Lortie et al. (2004). A global analysis indicates that the costs and benefits of harboring associated species in alpine habitats depends on the composition of the plant community assemblage present (Schöb et al. 2014). Lazarina et al. (2013) implied that the observed variations in SAR are correlated with beta diversity because they reflect the differentiation of species composition among habitats. The roles of clonal spreading and of generative reproduction depend on the growth form of the species (Klimeš 1999). A strong dominant species affects the shape of SAR curve through indirect controls over the internal environment and the structure of plant communities (Rejmének and Rosén 1992; Singh et al. 1996).

In this study, alpine meadows are dominated by Kobresia pygmaea (Wu et al. 2014b), which outcompetes other species for space using nonsexual clone. In contrast, grasses and legumes reproduce through sexual seeds. In addition, $K$. pygmaea allocates more biomass to roots to adapt to cold and humid habitats, and its dead roots take more than ten years to decompose (Zhou 2001). Thus, $K$. pygmaea generally forms a dense mat of both alive and dead roots within the topsoils in alpine meadows. The lateral extent of these root systems can limit the dispersal and establishment 
of legumes and grasses. The dominant species may affect the establishment of other species in alpine meadows on the Tibetan Plateau in this manner. Forbs in alpine meadows allocate more biomass to reproductive organs (Wu et al. 2013a) and can avoid direct competition with dominant sedges. Therefore, the SAR curves for forbs have significant larger intercept and slope values than those of the other three functional groups analysed in our study (Figure 3). Alpine steppes are much sparser than meadows, and in steppes, the dominant speciesStipa purpurea-disperses by sexual reproduction (Wu et al. 2014b). No eviedent competition or faciliation might exist among plant individuals in sparse steppe communities. Species dispersal and establishment in alpine steppes are likely limited by envionmental filers and adaptive strategies employed by different funtional groups. On the Qinghai-Tibetan Plateau, the responses of richness to climate remarkably depended on life-forms, water availility predominantly regulated the species richness patteren of herbaceous plants (Yan et al. 2013). Therefore, precipitation functions as an overwhelming filer and impacts spatial variations in both species richness and functional group composition on the north-western Tibetan alpine grasslands ( $\mathrm{Hu}$ et al. 2010; Shi et al. 2014; $\mathrm{Wu}$ et al. 2014c). According to $\mathrm{Wu}$ et al. (2013a) and $\mathrm{Ma}$ et al. (2010a), alpine grassland plants respond to climatic gradients across the Northern Tibetan Plateau by differentiating their biomass allocation strategies. For example, grasses in alpine steppes allocate more biomass reproductive organs while legumes invest more in roots to adapt the drier habitats (Wu et al. 2013a). Therefore, grasses have relatively larger intercept and slope than other functional groups; however, no significant difference was found in either the intercept or slope among grasses, legumes and sedges (Figure 3). Texeira and Altesor (2009) reported that species coexistence and the apparent stability of plant communities at small scales could be linked with the diversity of growth forms and their specifical mobility stragegies. The different dispersal capabilities of dominant species between meadows and steppes might partly explained by the differences in SAR parameters analyzed in this study. Forbs may have the largest intercept and slope values (Figure 3) because of their wide niches, i.e., forbs were reported to have large variations in biomass allocation fractions or ratios by $\mathrm{Wu}$ et al. (2013a).

Livestock grazing can affect plant species composition and spatial distribution because heavy stocking rates ensures the dominance of a few species while leaves niches for scattered individuals of other species (Hiernaux 1998). In the Tibetan alpine meadows, grazing only during cold months might result relatively greater both species richness and spatial variation than grazing all year round (Chen et al. 2008). Another studies found that grazing disturbance favored an increasing in species abundance for smaller-seeded plants but not for the large-seed ones in alpine meadow communities on the Qinghai-Tibetan Plateau (Wu et al. 2014a). Semi-logarithmic SAR curves hold true at very fine scales for both alpine meadow and steppe communities on the Northern Tibetan Plateau; however, the properties of the SAR curves for both meadow and steppe communities are closely related to compositional differences in functional groups that have specifically evolved adaptive strategies to survive in the alpine habitats on the Tibetan Plateau. The different SAR patterns should be linked with the dispersal capabilities and functional traits of the species in the alpine grasslands communities. Therefore, further studies related to species richness should first specify the varying responses of different functional groups to changes in climate and grazing disturbances.

\section{Acknowledgements}

This study was jointly supported by the Chinese Academy of Sciences (Grant Nos. XDB03030401, KZCXZ-XB3-08), the State Scholarship Fund of the China Scholarship Council (Grant No. 201400260118) and the International Postdoctoral Exchange Fellowship Program 2014 by the Office of China Postdoctoral Council (Grant No. 20140041).

Electronic Supplementary Material: Supplementary material (Appendix 1) is available in the online version of this article at http://dx.doi.org./10.1007/s11629-014-3166-2. 


\section{References}

Arrhenius O (1921) Species and area. Journal of Ecology 9: 95-99.

Auerbach M, Shmida A (1987) Spatial scale and the determinants of plant species richness. Trends in Ecology and Evolution 2: 238-242. DOI: 10.1016/0169-5347(87)90005-X

Barnett DT, Stohlgren TJ (2003) A nested-intensity design for surveying plant diversity. Biodiversity and Conservation 12: 255-278. DOI: 10.1023/A:1021939010065

Bell G (2001) Ecology - Neutral macroecology. Science 293: 2413-2418. DOI: 10.1126/science.293.5539.2413

Cadotte M, Albert CH, Walker SC (2013) The ecology of differences: assessing community assembly with trait and evolutionary distances. Ecology Letters 16: 1234-1244. DOI: 10.1111/ele.12161

Cao J, Holden NM, Lu XT, et al. (2011) The effect of grazing management on plant species richness on the QinghaiTibetan Plateau. Grass and Forage Science 66: 333-336. DOI: 10.1111/j.1365-2494.2011.00793.x

Cao JJ, Yeh ET, Holden NM, et al. (2013) The effects of enclosures and land-use contracts on rangeland degradation on the Qinghai-Tibetan plateau. Journal of Arid Environments 97: 3-8. DOI: 10.1016/j.jaridenv.2013.05.002

Carey S, Harte J, Moral R del (2006) Effect of community assembly and primary succession on the species-area relationship in disturbed ecosystems. Ecography 29: 866-872. DOI: $10.1111 /$ j.2006.0906-7590.04712.x

Chase JM, Myers JA (2011) Disentangling the importance of ecological niches from stochastic processes across scales. Philosophical Transactions of the Royal Society B-Biological Sciences 366: 2351-2363. DOI: 10.1098/rstb.2011.0063

Chen J, Yamamura Y, Hori Y, et al. (2008) Small-scale species richness and its spatial variation in an alpine meadow on the Qinghai-Tibet Plateau. Ecological Research 23: 657-663. DOI: 10.1007/s11284-007-0423-7

Chiarucci A, Viciani D, Winter C, et al. (2006) Effects of productivity on species-area curves in herbaceous vegetation: evidence from experimental and observational data. Oikos 115 475-483. DOI: 10.1111/j.2006.0030-1299.15116.x

de Bello F, Lepš J, Sebastià MT (2007) Grazing effects on the species-area relationship: Variation along a climatic gradient in NE Spain. Journal of Vegetation Science 18: 25-34. DOI: 10.1111/j.1654-1103.2007.tbo2512.x

Dengler J, Oldeland J (2010) Effects of sampling protocol on the shapes of species richness curves. Journal of Biogeography 37: 1698-1705. DOI: 10.1111/j.1365-2699.2010.02322.x

Desilets P, Houle G (2005) Effects of resource availability and heterogeneity on the slope of the species-area curve along a floodplain-upland gradient. Journal of Vegetation Science 16: 487-496. DOI: 10.1111/j.1654-1103.2005.tbo2389.x

Gerstner K, Dormann CF, Vaclavik T, et al. (2014) Accounting for geographical variation in species-area relationships improves the prediction of plant species richness at the global scale. Journal of Biogeography 41: 261-273. DOI: 10.1111/ Jbi.12213

Gleason HA (1922) On the relation between species and area. Ecology 3: 158-162. DOI: 10.2307/1929150

Gleason HA (1925) Species and area. Ecology 6: 66-74. DOI: $10.2307 / 1929241$

Gray JS, Ugland KI, Lambshead J (2004) On species accumulation and species-area curves. Global Ecology and Biogeography 13: 567-568. DOI: 10.1111/j.1466-822X.2004. 00138.x

He FL, Hubbell SP (2011) Species-area relationships always overestimate extinction rates from habitat loss. Nature 473: 368-371. DOI: 10.1038/Natureo9985

Hedberg P, Kozub L, Kotowski W (2014) Functional diversity analysis helps to identify filters affecting community assembly after fen restoration by top-soil removal and hay transfer.
Journal for Nature Conservation 22: 50-58. DOI: 10.1016/ j.jnc.2013.08.004

Hiernaux P (1998) Effects of grazing on plant species composition and spatial distribution in rangelands of the Sahel. Plant Ecology 138: 191-202. DOI: 10.1023/ A:1009752606688

Houle G (1990) Species-area relationship during primary succession in granite outcrop plant-communities. American Journal of Botany 77: 1433-1439. DOI: 10.2307/2444753

$\mathrm{Hu}$ ZM, Yu GR, Fan JW, et al. (2010) Precipitation-use efficiency along a 4500-km grassland transect. Global Ecology and Biogeography 19: 842-851. DOI: $10.1111 / \mathrm{j} .1466-8238$. 2010.00564.x

Hurlbert SH (1984) Pseudoreplication and the design of ecological field experiments. Ecological Monographs 54: 187211. DOI: $10.2307 / 1942661$

Keeley JE, Fotheringham C (2009) Plot shape effects on plant species diversity measurements. Journal of Vegetation Science 16: 249-256. DOI: 10.1111/j.1654-1103.2005. tbo2362.x

Klimeš L (1999) Small-scale plant mobility in a species-rich grassland. Journal of Vegetation Science 10: 209-218. DOI: $10.2307 / 3237142$

Lawton JH (1999) Are there general laws in ecology? Oikos 84: 177-192.

Lazarina M, Kallimanis AS, Sgardelis SP (2013) Does the universality of the species-area relationship apply to smaller scales and across taxonomic groups? Ecography 36: 965-970. DOI: $10.1111 / j .1600-0587.2013 .00149 . x$

Leps J, Stursa J (1989) Species-area curve, life-history strategies, and succession - a field-test of relationships. Vegetatio 83: 249-257. DOI: 10.1007/Bfooo31697

Li XJ, Zhang XZ, Wu JS, et al. (2011) Root biomass distribution in alpine ecosystems of the northern Tibetan Plateau. Environmental Earth Sciences 64: 1911-1919. DOI: 10.1007/s12665-011-1004-1

Lomolino MV (2000) Ecology's most general, yet protean pattern: the species-area relationship. Journal of Biogeography 27: 17-26. DOI: 10.1046/j.1365-2699.200o. 00377.x

Lortie CJ, Brooker RW, Choler P, et al. (2004) Rethinking plant community theory. Oikos 107: 433-438. DOI: 10.1111/j.00301299.2004.13250.x

Ma WL, Shi PL, Li WH, et al. (2010a) Changes in individual plant traits and biomass allocation in alpine meadow with elevation variation on the Qinghai-Tibetan Plateau. Science China Life Sciences 53: 1142-1151. DOI: 10.1007/s11427-0104054-9

Ma WH, He JS, Yang YH, et al. (2010b) Environmental factors covary with plant diversity-productivity relationships among Chinese grassland sites. Global Ecology and Biogeography 19: 233-243. DOI: 10.1111/j.1466-8238.2009.00508.x

Morgan JW, Wong NK, Cutler SC (2011) Life-form species-area relationships in a temperate eucalypt woodland community. Plant Ecology 212: 1047-1055. DOI: 10.1007/s11258-0109885-8

Olsen SL, K. Klanderud (2014) Biotic interactions limit species richness in an alpine plant community, especially under experimental warming. Oikos 123: 71-78. DOI: $10.1111 / \mathrm{j} .1600-$ 0706.2013.00336.x

Ramsay PM, Oxley ERB (1997) The growth form composition of plant communities in the ecuadorian páramos. Plant Ecology 131: 173-192. DOI: 10.1023/a:1009796224479

Rejmének M, E. Rosén. (1992) Influence of colonizing shrubs on species-area relationships in alvar plant communities. Journal of Vegetation Science 3: 625-630. DOI: 10.2307/ 3235829 
Schöb C, Michalet R, Cavieres LA, et al. (2014) A global analysis of bidirectional interactions in alpine plant communities shows facilitators experiencing strong reciprocal fitness costs. New Phytologist 202: 95-105. DOI: 10.1111/nph.12641

Scheiner SM (2003) Six types of species-area curves. Global Ecology and Biogeography 12: 441-447. DOI: 10.1046/j.1466822X.2003.00061.x

Scheiner SM (2004) A melange of curves - further dialogue about species-area relationships. Global Ecology and Biogeography 13: 479-484. DOI: 10.1111/j.1466-822X.2004. 00127.x

Scheiner SM (2009) The terminology and use of species-area relationships: a response to Dengler (2009). Journal of Biogeography 36: 2005-2008. DOI: 10.1111/j.1365-2699.2009. 02164.X

Shen GC, Yu MJ, Hu XS, et al. (2009) Species-area relationships explained by the joint effects of dispersal limitation and habitat heterogeneity. Ecology 90: 3033-3041. DOI: 10.1890/ 08-1646.1

Shi Y, Wang Y, Ma Y, et al. (2014) Field-based observations of regional-scale, temporal variation in net primary production in Tibetan alpine grasslands. Biogeosciences 11: 2003-2016. DOI: $10.5194 / \mathrm{bg}-11-2003-2014$

Shmida A, Wilson MV (1985) Biological determinants of species-diversity. Journal of Biogeography 12: 1-20. DOI: 10. 2307/2845026

Singh JS, Bourgeron P, Lauenroth WK (1996) Plant species richness and species-area relations in a shortgrass steppe in Colorado. Journal of Vegetation Science 7: 645-650. DOI: $10.2307 / 3236376$

Stegen JC, Swenson NG (2009) Functional trait assembly through ecological and evolutionary time. Theoretical Ecology 2: 239-250. DOI: $10.1007 / \mathrm{s} 12080-009-0047-3$

Stohlgren TJ, Falkner MB, Schell LD (1995) A ModifiedWhittaker Nested Vegetation Sampling Method. Vegetatio 117: 113-121. DOI: $10.1007 /$ Bfooo 45503

Texeira M, Altesor A (2009) Small-scale spatial dynamics of vegetation in a grazed Uruguayan grassland. Austral Ecology 34: 386-394. DOI: 10.1111/j.1442-9993.2009.01940.x

Tjorve E (2003) Shapes and functions of species-area curves: a review of possible models. Journal of Biogeography 30: 827835. DOI: $10.1046 / j .1365-2699.2003 .00877 . x$

Tjorve E (2009) Shapes and functions of species-area curves (II): a review of new models and parameterizations. Journal of Biogeography 36: 1435-1445. DOI: 10.1111/j.1365-2699.2009. 02101.x

Tjorve E, Tjorve KM (2008) The species-area relationship, selfsimilarity, and the true meaning of the z-value. Ecology 89: 3528-3533. DOI: 10.1890/07-1685.1

Turner WR, Tjorve E (2005) Scale-dependence in species-area relationships. Ecography 28: 721-730. DOI: 10.1111/j.2005. 0906-7590.04273.x

Ulrich W, Buszko J (2007) Sampling design and the shape of species-area curves on the regional scale. Acta OecologicaInternational Journal of Ecology 31: 54-59. DOI: 10.1016/ j.actao.2006.03.005

Wang Z, Luo TX, Li RC, et al. (2013) Causes for the unimodal pattern of biomass and productivity in alpine grasslands along a large altitudinal gradient in semi-arid regions. Journal of Vegetation Science 24: 189-201. DOI: 10.1111/ j.1654-1103.2012.01442.x

Whittaker RJ, Matthews TJ, Fernández-Palacios JM (2014) The varied form of species-area relationships. Journal of Biogeography 41: 209-210. DOI: 10.1111/jbi.12256

Whittaker RJ, Triantis KA (2012) The species-area relationship: an exploration of that 'most general, yet protean pattern'. Journal of Biogeography 39: 623-626. DOI: $10.1111 / \mathrm{j} \cdot 1365^{-}$ 2699.2012.02692.x

Wu GL, Shang ZH, Zhu YJ, et al. (2014a) Species abundanceseed size patterns within a plant community affected by grazing disturbance. Ecological Applications. DOI: 10.1890/14-0135.1

Wu JS, Shen ZX, Zhang XZ (2014b) Precipitation and species composition primarily determine the diversity-productivity relationship of alpine grasslands on the Northern Tibetan Plateau. Alpine Botany 124: 13-25. DOI: 10.1007/sooo35014-0125-Z

Wu JS, Shen ZX, Shi PL, et al. (2014c) Effects of grazing exclusion on plant functional group diversity alpine grasslands along a precipitation gradient on the Northern Tibetan Plateau. Arctic Antarctic and Alpine Research 46: 419-429. DOI: 10.1657/1938-4246-46.2.419

Wu JS, Shen ZX, Zhang XZ, et al. (2013a) Biomass allocation patterns of alpine grassland species and functional groups along a precipitation gradient on the Northern Tibetan Plateau. Journal of Mountain Science 10: 1097-1108. DOI 10.1007/s11629-013-2435-9

Wu JS, Zhang XZ, Shen ZX, et al. (2013b) Grazing-exclusion effects on aboveground biomass and water-use efficiency of alpine grasslands on the Northern Tibetan Plateau. Rangeland Ecology \& Management 66: DOI: 454-461. Doi 10.2111/Rem-D-12-00051.1

Wu JS, Zhang XZ, Shen ZX, et al. (2014d) Effects of livestock exclusion and climate change on aboveground biomass accumulation in alpine pastures across the Northern Tibetan Plateau. Chinese Science Bulletin 59: 4332-4340. DOI: 10.1007/s11434-014-0362-y

Wu JS, Zhang XZ, Shen ZX, et al. (2012) Species richness and diversity of alpine grasslands on the Northern Tibetan Plateau: effects of grazing exclusion and growing season precipitation. Journal of Resources and Ecology 3: 236-242. DOI: 10.5814/ j.issn.1674-764x.2012.03.006

Yan YJ, Yang X, Tang Z (2013) Patterns of species diversity and phylogenetic structure of vascular plants on the QinghaiTibetan Plateau. Ecology and Evolution 3: 4584-4595. DOI: 10.1002/ece3.847

Yang YH, Fang JY, Fay PA, et al. (2010) Rain use efficiency across a precipitation gradient on the Tibetan Plateau. Geophysical Research Letters 37: L15702. DOI: 10.1029/ 2010 glo43920

Yang YH, Fang JY, Pan YD, et al. (2009) Aboveground biomass in Tibetan grasslands. Journal of Arid Environments 73: 9195. DOI: 10.1016/j.jaridenv.2008.09.027

Yu FH, Krusi B, Schutz M, et al. (2008) Plant communities affect the species-area relationship on Carex sempervirens tussocks. Flora 203: 197-203. DOI: 10.1016/j.flora.2007. 03.002

Zhou XM (2001) Chinese Kobresia Meadow. Science Press, Beijing, China. pp 155-16o. (In Chinese) 